See discussions, stats, and author profiles for this publication at: https://www.researchgate.net/publication/307552592

\title{
$\beta$-TCP Produced through the Starch Consolidation Technique
}

Article in Materials Science Forum · August 2016

DOI: 10.4028/www.scientific.net/MSF.869.902

CITATIONS

0

6 authors, including:

Sylma Carvalho Maestrelli

Universidade Federal de Alfenas

41 PUBLICATIONS 138 CITATIONS

SEE PROFILE

Some of the authors of this publication are also working on these related projects:

Project Biomining View project

Concrete Formulations Properties View project

\section{READS}

46

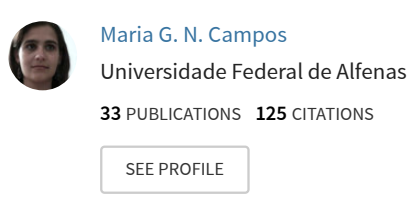




\title{
$\beta$ - TCP Produced Through the Starch Consolidation Technique
}

\author{
T. N. Gondim ${ }^{1, a}$, S. C. Maestrelli ${ }^{1, b}$, M. G. N. Campos ${ }^{1, c}$, M. Z. Minucci ${ }^{1, d}$, \\ R. F. C. Marques ${ }^{2, e}$, R. S. Fernandes ${ }^{1, f}$ \\ ${ }^{1}$ Institute of Science and Technology, Federal University of Alfenas, Poços de Caldas (MG), Brazil. \\ ${ }^{2}$ Institute of Chemistry, UNESP, Araraquara (SP), Brazil. \\ atuliogondim@oi.com.br, bsylma.maestrelli@unifal-mg.edu.br, cmaria.campos@unifal-mg.edu.br, \\ dmila_391@hotmail.com, eurgentissimo@gmail.com, 'sampaio@unifal-mg.edu.br
}

Keywords: $\beta-T C P$, starch consolidation, synthetic bone grafts.

\begin{abstract}
Synthetic materials based on calcium such as hydroxyapatite and beta-TCP are one of the main bone substitutes because of their biocompatibility. The starch consolidation is a simple and low cost technique which is based on using the starch as a gel former in the presence of water, turning possible its use as a conforming and main element to form pores. In this project,samples were produced trough starch conformation by fixing the percentage of solids (beta-TCP) in 50\% and varying the amount and type of starch (corn and potato) in 10, 20, 30 and $40 \%$. The results showed that it was possible to obtain porous samples by using corn and potato starches. Moreover, the percentage of starch added strongly influenced porosity and resistance of the samples. The addition of $30 \%$ or more of starch reduced the mechanical resistance of samples which limited their use.
\end{abstract}

\section{Introduction}

The development of implantology and regenerative surgeries has been motivating by the search for new biomaterials, as well as the reactions that happen in the tissue-implant interface. To install the dental implant or in the case of reconstructive surgeries, mostly it is necessary a bone augmentation of the receiving region trough bone grafts [1].

Hydroxyapatite and $\beta$-TCP are materials based in calcium phosphate, one of the main synthetic bone substitute [2]. These materials have clinical use as block or granules forms either porous or dense. Hydroxyapatite and $\beta$-TCP when in granules form can be easily adapted on the contour of the bone defects, they are chemically stable, do not have restriction for availability and also are not supposed to immune rejection [3].

For bone replacement, $\beta$-TCP can be synthetically obtained with high biocompatibility and similarities with the natural bone structure, being reabsorbed by the body and replaced by a new bone tissue. For bone grafts, $\beta$-TCP must show porosity in order to promote better penetration of the forming cell of bone (osteoblasts). Thus, the graft can be adhered to the implant area, working as a mold for the formation of the new bone. These pores must be integrated and have diameter between 100 e $200 \mu \mathrm{m}$ [4].

The obtaining of porous materials through starch consolidation is a directly consolidated technique based on the properties of gel formation of the starch in the presence of water, making possible its use as a conforming and main element to make pores [5]. This technique allows a good control of porosity of the samples through the process of gelatinization of the starch.

Due to the applicability of $\beta$-TCP in bone regeneration, in bone defects or bone cavities, this project aimed to obtain and characterize ceramics bodies of $\beta$-TCP, by the conformation technique through the starch consolidation.

\section{Materials and methods}

Corn starch was produced by the company Unilever Bestfoods Brasil LTDA and the potato one was produced by Yoki Alimentos S/A - the values of density are, respectively, $1.52 \mathrm{~g} / \mathrm{cm}^{3}$ and 
$1.54 \mathrm{~g} / \mathrm{cm}^{3}$. The $\beta$-TCP ( $\beta$ tricalcium phosphate) was produced by the company Procell Biologic, located in São Carlos -SP - Brazil; its density is $3.16 \mathrm{~g} / \mathrm{cm}^{3}$. For the system deflocculation, a dispersant named Disperlan LA (ammonium polyacrylate) was used. This dispersant was produced by Lamberti Brasil Produtos Quimicos LTDA.

Composition volumes of $3.0 \mathrm{~cm}^{3}$ were studied to prepareceramic bodies based on $\beta$-TCP and starch and their percentage of solids was $50 \%(\mathrm{v} / \mathrm{v})$. The mass content of starch were varied to 10 , 20,30 e $40 \%$, for both corn and potato starches.

The mass utilized for the conformation process was calculated based on starch and $\beta$-TCP specific mass. The suspensions were shed in cylindrical impermeable molds made of plastic $(2 \mathrm{~cm}$ of diameter and $6 \mathrm{~cm}$ of height) and taken to the oven for two hours to start the gelatinization process - for corn starch, the temperature was $65^{\circ} \mathrm{C}$ and for potato starch it was $75^{\circ} \mathrm{C}$. Then, the temperature was increased to $110^{\circ} \mathrm{C}$ and the mold and body were kept there for 45 minutes.

After the drying process, the bodies were burned at $1100^{\circ} \mathrm{C}$ for 2 hours in a heating rate of $10^{\circ} \mathrm{C} / \mathrm{min}$, to eliminate organic products and to promote the increasing of mechanical resistance of the samples.

The samples were characterized by measurements of the apparent porosity (by using the Archimedes principle) and Sacnning Electron Microscopy (SEM).

\section{Results and discussion}

Apparent porosity results are shown at Fig. 1 for the samples with $50 \%$ of solids at the following concentrations: $10 \%, 20 \%, 30 \%$ e $40 \%$ of corn and potato starches.

The addition of corn and potato starches increased the porosity of the ceramic pieces that were more evident at the concentrations of $30 \%$ and $40 \%$. It can be observed that potato starch promoted, in all compositions, higher porosity when compared to corn one. It is probably due to the size of the grains, which is larger for potato starch.

For the concentration of $40 \%$ corn and potato starch, it could be observed that the higher porosity (73 and $75 \%$ ) caised the disintegration of the pieces. This problem was not observed on the other concentrations.

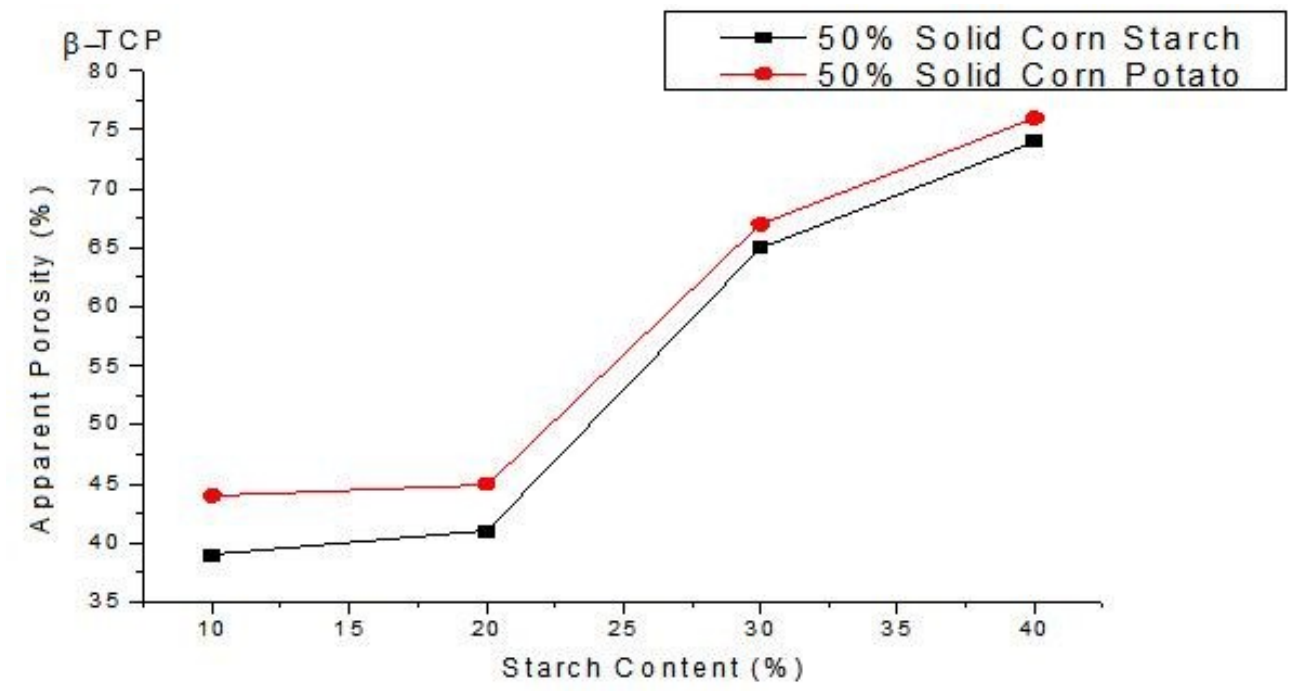

Fig. 1 - Apparent Porosity of $\beta$-TCP according to the content of corn starch and potato.

The increase of the apparent porosity was caused by the elimination of organic materials during the burn process. The starch is the mainly responsible for the formation of pores.

Through scanning electron microscopy, it could be observed pores distribution and size in the surface of ceramics blocks obtained at different concentrations of corn and potato starches for samples with $50 \%$ of solids.

Figure 2 presented the micrographs of pieces with 10, 20, 30 and $40 \%$ of corn starch and $50 \%$ of solids, represented by a,b,c and d, respectively. Figure 3 shows pieces with 10, 20, 30 and 40\% of potato starch and $50 \%$ of solids, represented by a,b,c and d, respectively. 

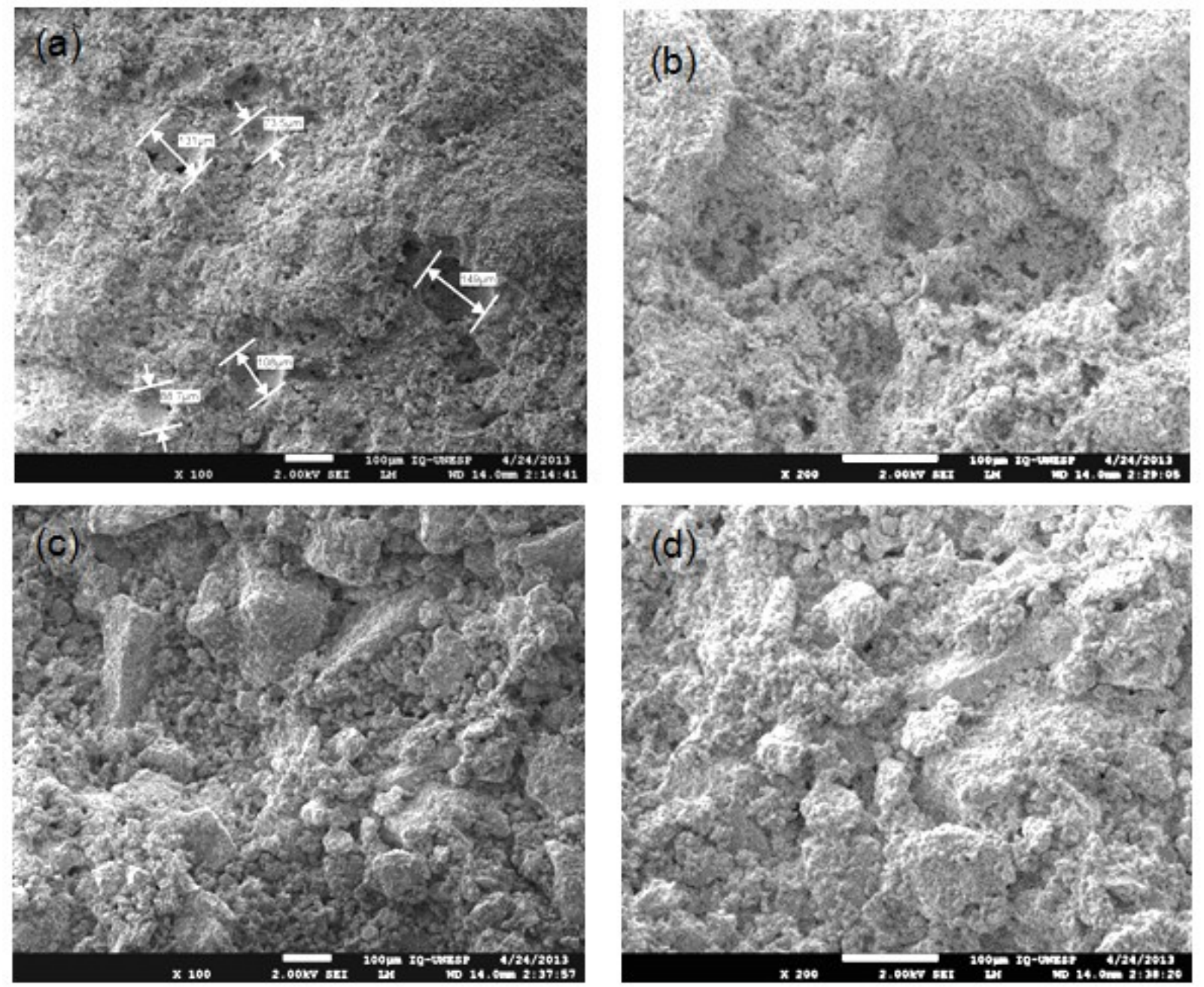

Fig. 2 - Micrographs of the samples with corn starch at 50\% solids. (A) 10\% and 100X, (b) 20\% and 200X, (c) $30 \%$ and 100X (d) 40\% and 200X.

The formation of spherical pores with diameters greater than $100 \mu \mathrm{m}$ and well defined were observed, due to the elimination of the corn starch in blocks with concentration of $10 \%$ and $20 \%$ (Fig. 2 (a) and (b)). It is noteworthy the importance of the presence of interconnected pores with diameters around $100 \mu \mathrm{m}$, allowing the penetration of bone forming cells, facilitating bone formation.

The samples with $50 \%$ of solid and with 10 and $20 \%$ of corn starch (Fig. 2 (a) and 9b)) showed good resistance, which would allow the grafting in bone defects functioning as a scaffold for new bone formation. Samples with 30 and $40 \%$ of corn starch (Fig. 2 (c) and (d)) showed the surface of the porous ceramic material with larger porosity and smaller pores but with no well defined as those found in samples with 10 and $20 \% \%$ of corn starch. These samples presented low resistance to manipulation due to the high porosity (greater amount of pores, but smaller pores), which would cause a difficulty in maintaining intact the structure of the sample. 

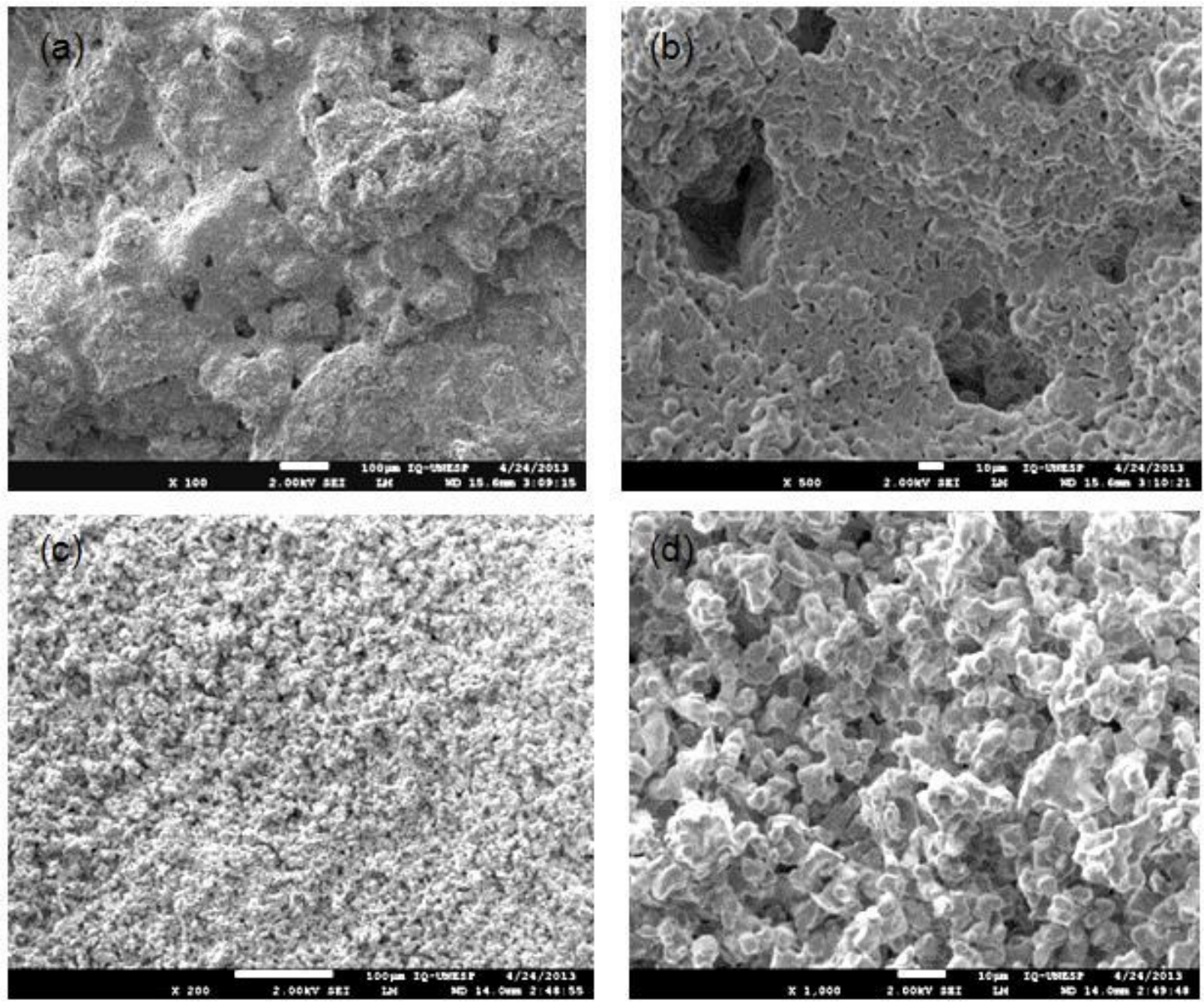

Fig. 3 - Micrographs of the samples with potato starch at 50\% solids. (A) $10 \%$ and 100X, (b) $20 \%$ and 500X, (c) $30 \%$ and $200 \mathrm{X}$ (d) $40 \%$ and $1000 \mathrm{X}$.

According to Fig. 3 (a) and (b), it was observed high porosity with large and well-defined pores with diameters around $60 \mu \mathrm{m}$, which could prevent the penetration of bone forming cells and, therefore, bone formation. The pieces with 10 and $20 \%$ of potato starch showed good resistance to handling and small pores dispersed in the ceramic matrix of $\beta$-TCP.

For the concentrations of 30 and $40 \%$ of potato starch (Fig. 3 (c) and (d)), a large number of pores of diameter around $10 \mu \mathrm{m}$ were observed. In addition, the specimens showed low resistance, which could adversely affect the processes of bone integration in implants.

When comparing the parts with $10 \%$ corn starch and $10 \%$ potato starch, it appears that those with corn starch showed higher and more well defined pores, although both exhibited similar porosity.

The ceramic pieces of $\beta$-TCP in the concentration of 30 and $40 \%$ of potato starch (Fig. 3 (c) and (d)) showed large amount of distributed pores with small diameter and low mechanical strength, both poor factors in the case of bone integration process for bone implants.

\section{Conclusions}

Through molding technique for consolidation with starch, $\beta$-TCP blocks of different interconnected porosity were obtained, which would allow its applicability in bone grafts.

For blocks with $10 \%$ and $20 \%$ of potato and corn starches, the blocks showed good resistance of manipulation, with pores with diameter around $100 \mu \mathrm{m}$, which enable bone formation in bone implants. The parts containing 30 and $40 \%$ of corn and potato starches exhibited low resistance to 
handling due to the high porosity, besides small pores (about $10 \mu \mathrm{m}$ and $60 \mu \mathrm{m}$ ), which could adversely affect bone formation.

The molding technique using starch consolidation showed to be efficient in producing parts of biomaterials with $\beta$-TCP, that is a simple and low cost technique due to the simplicity of the materials involved.

\section{References}

[1] J.B. Neves: Implantodontia Oral. Enxertos Ósseos. (Traccio Primeira edição Belo Horizonte, 2001).

[2] J.F. Honig, H.A. Merten, J. Wiltfang: J. Craniofac. Surg. Vol. 9 (3) (1998), p. 260.

[3] A. Okazaki, T. Koshino, T. Saito, T. Takagi: Biomaterials Vol. 21 (5) (2000), p. 483.

[4] Y.K. Gonda, T. Okuda, Y. Shibata, M. Kamitakahara: Key Engineering Materials Vols. 396-398 (2009|), p. 253.

[5] A.F. Lemos, J.M.F. Ferreira: Mat. Sci Eng. Vol. 11 (2000), p. 35. 